\title{
Chronic idiopathic pulmonary hilar fibrosis A clinicopathological entity
}

\author{
MAGDI H. YACOUB ${ }^{1}$ and VERNON C. THOMPSON \\ The Brompton and London Chest Hospitals
}

Idiopathic pulmonary hilar fibrosis is a condition related to mediastinal fibrosis, characterized by localization of the fibrosing process to one or both pulmonary hila. This results in pulmonary hypertension and bronchial narrowing. Three patients suffering from this disease, in whom the diagnosis has been confirmed by thoracotomy, are reported. The clinical and pathological features are described and previously reported cases are reviewed. The syndrome is classified into two types, according to whether the obstruction affects mainly the pulmonary artery or veins. The disease is a self-limiting one but may lead to organic changes in the lungs causing severe disability.

Idiopathic mediastinal fibrosis is a rare condition characterized by the formation of remarkably dense fibrous tissue which engulfs and destroys surrounding structures (Knox, 1925; Erganian and Wade, 1943 ; Tubbs, 1946 ; Kunkel, Clagett, and McDonald, 1954 ; Cameron, Ing, Boyle, and Mathews, 1961). The condition usually affects the

'Present address: Harefield Hospital, Middlesex superior mediastinum, particularly the region of the superior vena cava, and, as pointed out by Barrett (1958), "the clinical hallmark of mediastinal fibrosis is the presence of venous hypertension in the catchment area of the superior vena cava.' Less commonly, the fibrosis affects other mediastinal structures, producing different clinicopathological syndromes depending on the

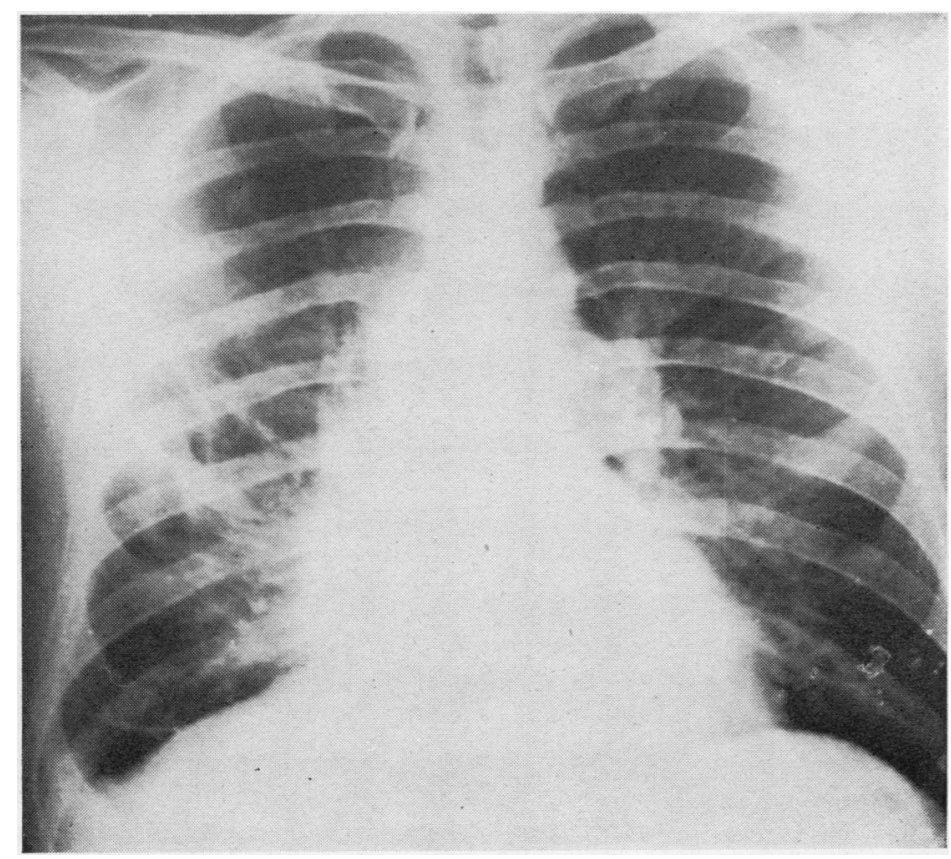

FIG. 1. Case 1. Chest radiograph. 
location of the fibrosing mass (Hache, Woolner, and Bernatz, 1962). When localized to the hilum of one or both lungs the fibrosis may produce profound changes in the structure and function of the affected lung. These changes give rise to a typical clinicopathological syndrome which may be diagnosed during life. In this paper, three patients with pulmonary hilar fibrosis are described and the clinicopathological changes are discussed.

\section{CASE REPORTS}

CASE 1 D. L., a sailor aged 30 years, complained of repeated haemoptyses for three years. He was admitted to the Brompton Hospital in June 1964. Clinical examination revealed no clubbing of the fingers and no lymph node enlargement. The jugular venous pressure was normal. The pulmonary component of the second sound was accentuated. There were few bilateral rhonci. The chest radiograph (Fig. 1) showed mild enlargement of the cardiac shadow and prominence of the pulmonary veins. The right lung was smaller than the left and there was evidence of pleural thickening and obliteration

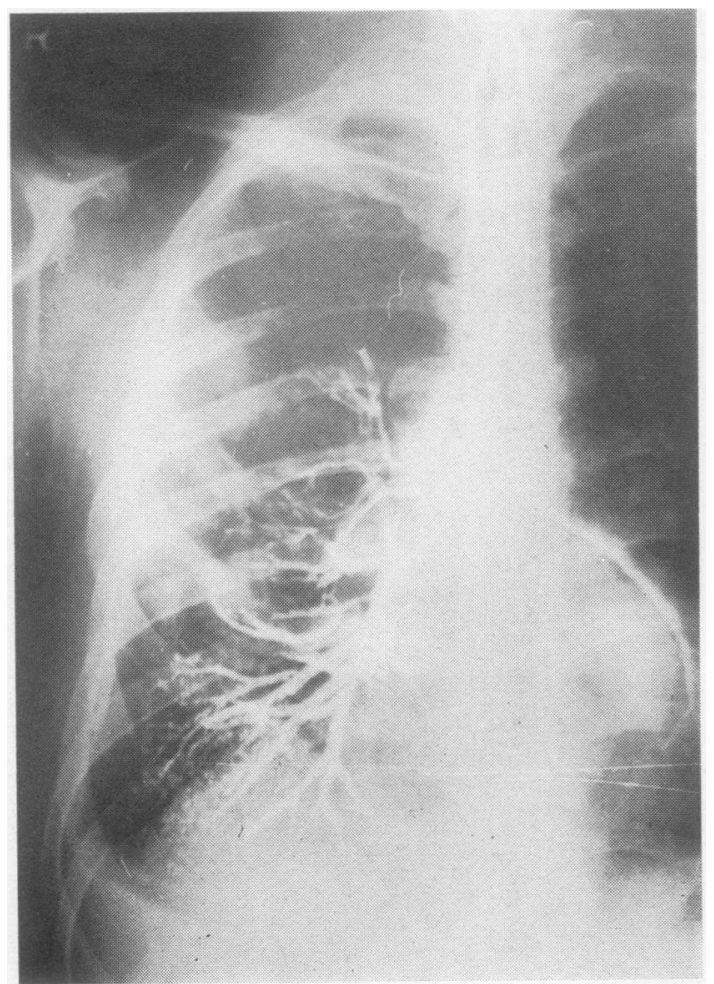

FIG. 2. Case 1. Bronchogram showing narrowing and distortion of middle lobe bronchus and adjoining intermediate lower lobe bronchi.

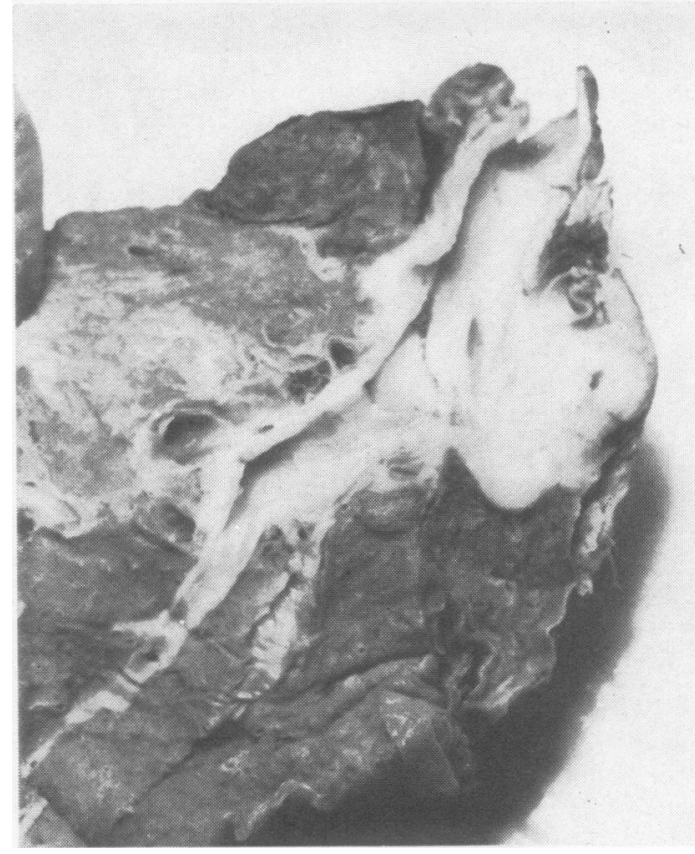

FIG. 3. Case 1. Section of the resected lung showing a dense mass obstructing the main pulmonary veins.

of the costophrenic angle on the right side. Linear opacities, probably pleural in origin, were present in the right mid-zone. Electrocardiograms showed right axis deviation. A bronchogram (Fig. 2) showed narrowing of the middle lobe bronchus and the adjoining part of the right main and lower lobe bronchi. The middle lobe bronchi were bronchiectatic and distorted. This was presumed to be the source of the haemoptysis.

Nine months later he was readmitted because of a recurrence of haemoptysis. Bronchoscopy during a severe bout of haemoptysis confirmed that the bleeding source was in the region of the middle lobe. Right thoracotomy was performed in May 1965 . There were many thick, extremely vascular adhesions between the parietal pleura and the chest wall. Both the parietal and visceral pleurae were thickened. There was a hard mass in the hilum measuring $3 \times 3$ in $(7.5 \times$ $7.5 \mathrm{~cm}$ ). The mass surrounded both pulmonary veins and extended into the substance of the lung. The intrapericardial segments of both pulmonary veins were solid up to their junction with the left atrium. Two frozen section specimens from the mass were reported as 'fibrous tissue'. As it was thought at that time that carcinoma of the lung was the most likely diagnosis, radical pneumonectomy with excision of a cuff of left atrium was performed.

Examination of the resected specimen showed very dense fibrosis mainly centred around the main pulmonary veins (Fig. 3). The lower vein was completely 
occluded while the upper vein lumen was reduced to a diameter of $2 \mathrm{~mm}$. The fibrous mass extended into the lung to surround the main bronchus and the pulmonary artery. The lumen of the main right pulmonary artery was not encroached upon. The fibrous tissue seemed to blend with the wall of the main bronchus. Histologically the mass consisted of relatively acellular collagenous tissue infiltrated by plasma cells in areas (Fig. 4). This tissue invaded and completely replaced the walls of the main pulmonary veins. The intrapulmonary large veins showed a thickened adventitia and intimal proliferation. The muscular arterioles showed marked thickening of the wall mainly due to intimal proliferation (Fig. 5). Some of them showed complete obliteration by organized thrombus with evidence of recanalization (Fig. 6). The alveolar walls were thickened and in some areas showed marked interstitial fibrosis with many heart failure cells in the alveolar sacs (Fig. 7). The pleura was markedly thickened and contained many muscular arterioles.

Postoperatively the patient made a smooth recovery. He was seen three years later when he was well and asymptomatic. A chest radiograph showed no abnormality of the left lung.

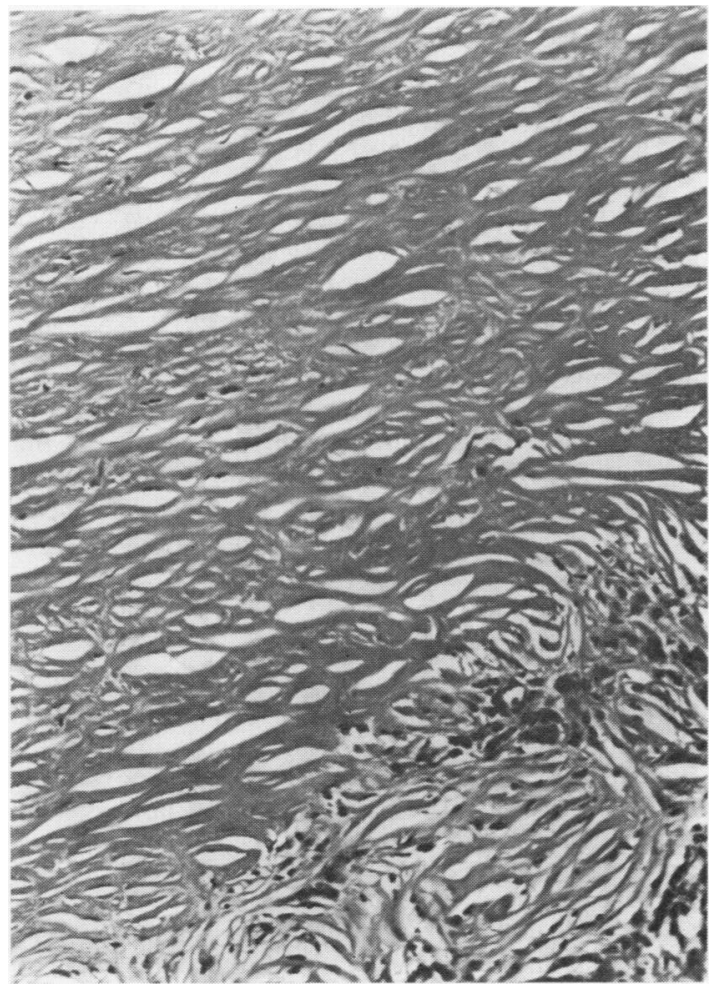

FIG. 4. Case 1. A section of the hilar mass showing dense collagenous tissue infiltrated in areas by plasma cells. $(\times 100)$.

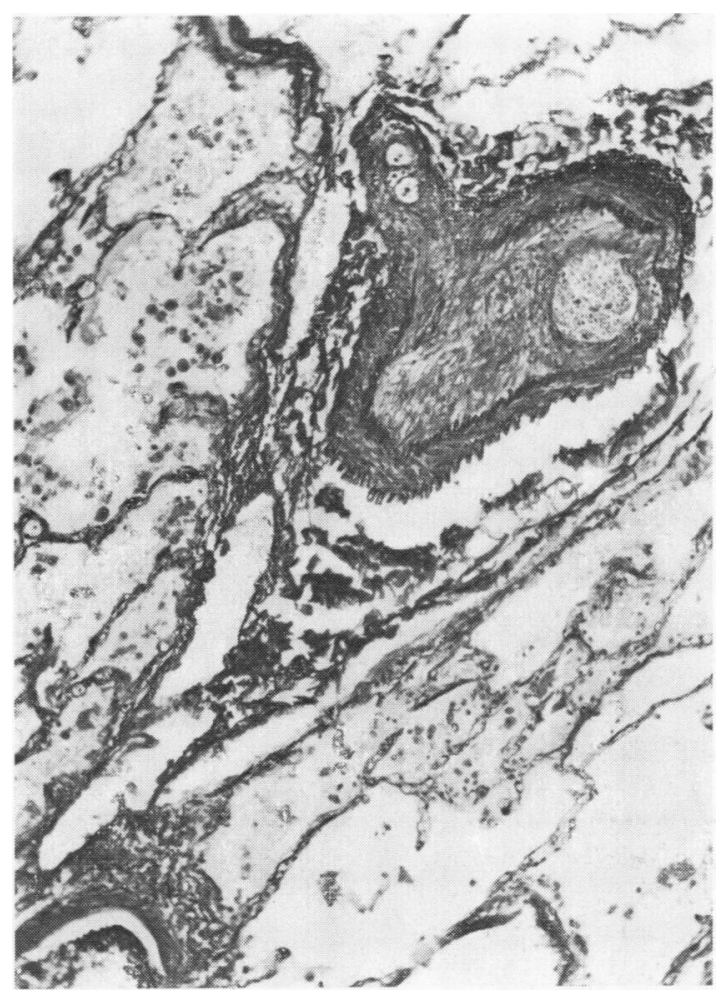

FIG. 5. Case 1. A section of the lung showing marked intimal proliferation of a pulmonary arteriole. $(\times 80)$.

CASE 2 A woman aged 32 years was admitted to the London Chest Hospital on 9 September, 1965. She had had cough and bloodstained sputum for one year. She had been seen at a chest clinic nine months previously when she was given a course of PAS and INAH for four months on a presumptive diagnosis of pulmonary tuberculosis, repeated sputum examination having been consistently negative. Clinical examination showed a healthy looking young woman There was no clubbing of the fingers and no lymph node enlargement. Chest examination showed signs of fibrosis of the left lung with a shift of the mediastinum to the left. The jugular venous pressure and the heart sounds were normal. Blood pressure was $210 / 80 \mathrm{mmHg}$. Abdominal examination showed no abnormality. The haemoglobin was $91 \%$ and the total white cell count was $5,000 / \mathrm{mm}^{3}$. The erythrocyte sedimentation rate was $33 \mathrm{~mm}$ in one hour. Blood urea was $21 \mathrm{mg} / 100 \mathrm{ml}$. A chest radiograph (Fig. 8) showed diminution in the size of the left lung with a shift of the mediastinum. The shadows of the left pulmonary artery and its branches were small and there were reticular shadows suggesting increased bronchial artery circulation similar to that seen in Fallot's tetralogy or the absence of one pulmonary artery. There was also evidence of pleural 


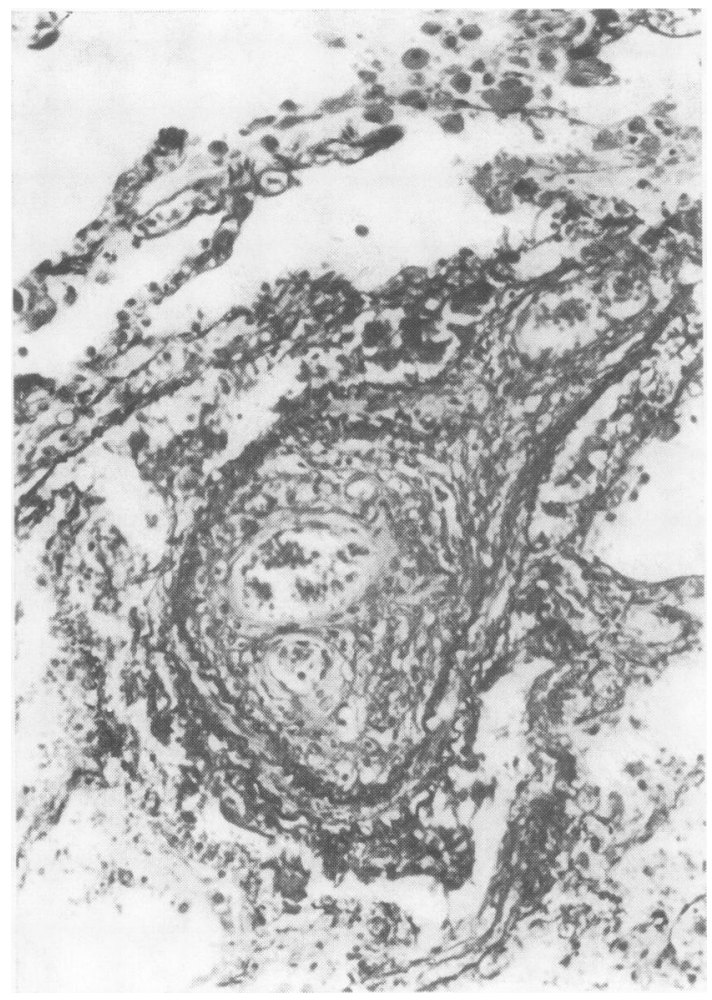

FIG. 6. Case 1. A section of the lung showing complete obstruction of a muscular arteriole with evidence of recanalization $(\times 100)$.

thickening. Bronchograms showed no abnormality on the right. On the left side there was absence of peripheral filling in both lobes, and the origins of the lower lobe bronchus and several of its branches were narrowed. Bronchoscopy confirmed narrowing of the left lower lobe bronchus and the mucous membrane looked congested and granular. She was discharged from hospital on 2 October, 1965.

During the next five months she had three bouts of severe haemoptysis and was readmitted to the London Chest Hospital on 4 February, 1966. Clinical examination, a chest radiograph, and laboratory investigations showed no change since her previous admission. Respiratory function tests showed an $\mathrm{FEV}_{1}$ of 1,700 (expected value 2,550$) \mathrm{ml}$ and a forced vital capacity of $2,700 \mathrm{ml}$. Sputum examination was repeatedly negative for acid-fast bacilli and malignant cells. A left thoracotomy was performed on 15 February, 1966. There were many vascular adhesions between the lung and the parietal pleura. There was a dense hilar mass surrounding the main left pulmonary artery extending to the region of the pulmonary veins and bronchus. No large abnormal bronchial arteries were seen. The hilum was dissected and some of the dense tissue on the pulmonary artery as well as a

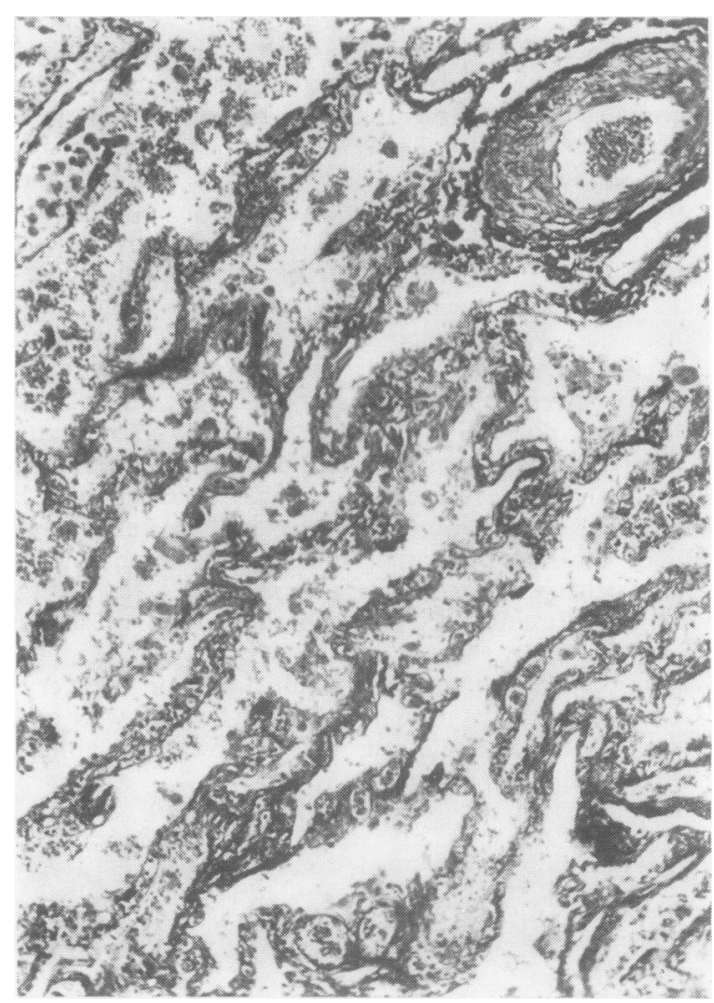

FIG. 7. Case 1. A section of the lung showing marked interstitial fibrosis with many 'heart failure cells' in the alveolar sacs. $(\times 100)$.

lymph node and surrounding tissue overlying the $\frac{\dot{\sigma}}{\partial}$ inferior pulmonary vein were removed for biopsy. This showed relatively acellular coarse bundles of collagen with areas infiltrated by plasma cells and lymphocytes almost identical with the tissue seen in 의 case 1.

She made a fairly smooth postoperative recovery $\frac{D}{0}$ but required bronchoscopic aspiration of secretions from the left lung on several occasions during the $\tilde{N}$ immediate postoperative period.

Pulmonary angiograms showed complete oblitera- N tion of the left pulmonary artery near its origin. The vessels on the right side (both arteries and veins) were normal. Radioactive scanning of the lungs using $\varrho$ radioactive xenon $\left({ }^{133} \mathrm{Xe}\right.$ ) (Fig. 9) showed no perfusion $\mathbb{D}$ of the left lung. An intravenous pyelogram was per- $\stackrel{\infty}{+}$ formed to exclude associated retroperitoneal fibrosis. 7 This showed normal kidneys and ureters. She con- ${ }^{\circ}$ tinues to lead a normal life and was last seen on $\mathbb{\mathbb { D }}$ 9 May, 1968, when it was noted that she had had $\frac{P}{\mathbb{D}}$ no further haemoptysis.

CASE 3 A woman aged 35 years was admitted to the Brompton Hospital in 1963. Since the age of 16 ? 


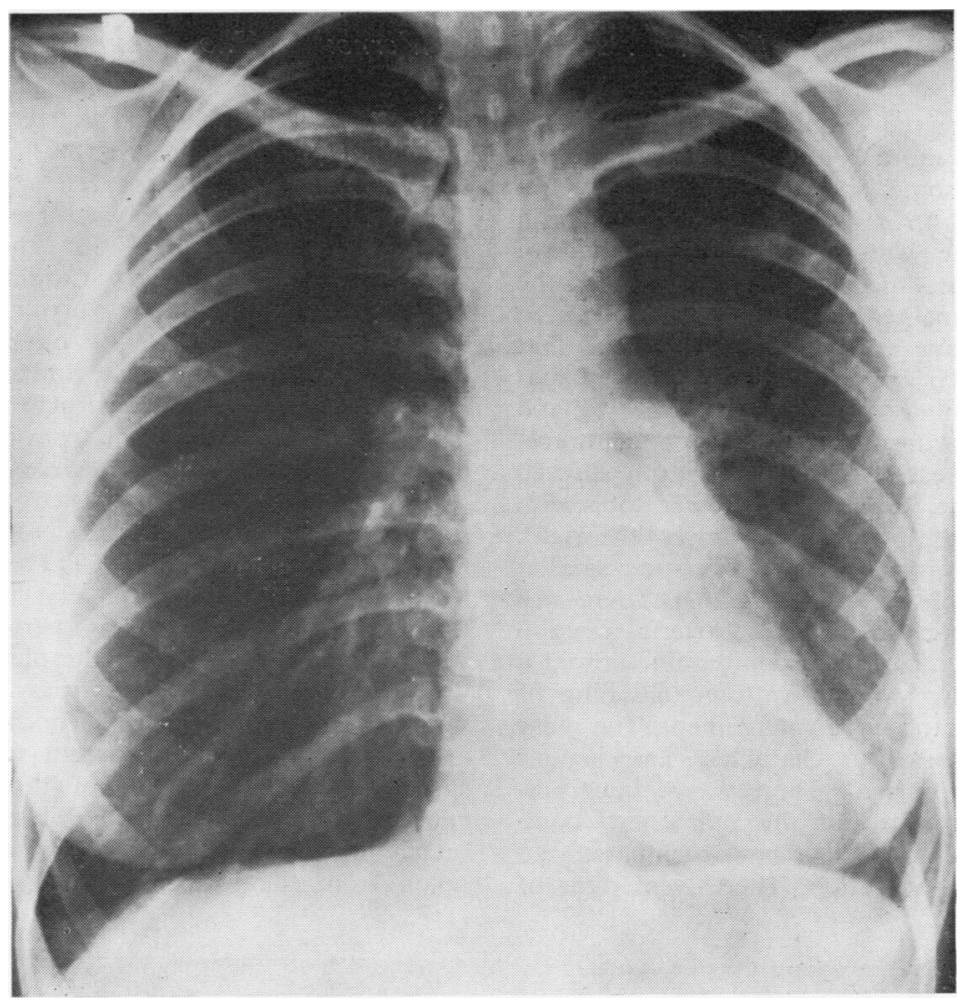

FIG. 8. Case 2. Chest radiograph showing a shift of the mediastinum to the left with diminution in the size of the left main pulmonary artery.

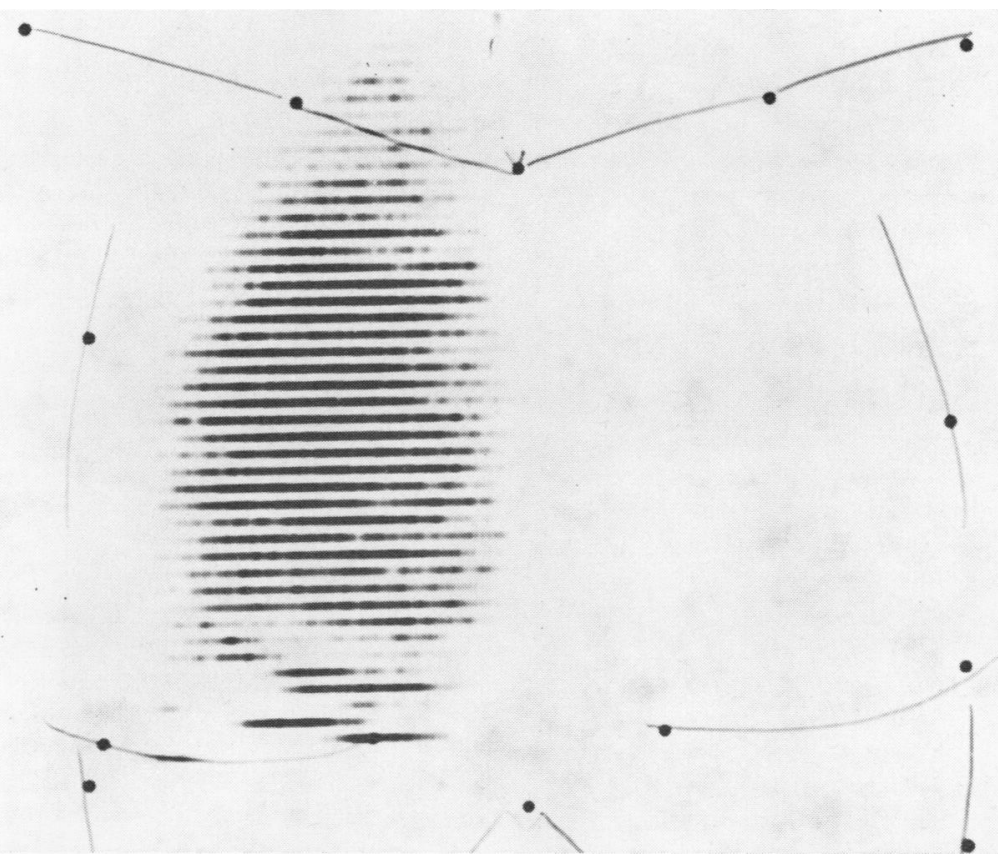

FIG. 9. Case 2. Lung scan showing complete absence of perfusion of the left lung. 
she had had repeated attacks of haemoptysis recurring every few months and varying in severity (up to $300 \mathrm{ml}$ on some occasions). A chest radiograph at the age of 16 showed a diffuse opacity in the right lower zone with a normal hilar shadow. Bronchoscopy at that time showed narrowing of the right upper lobe bronchus below the upper lobe, and the mucous membrane of the medial wall of that bronchus was granular and congested. Biopsy of that region produced a moderate amount of bleeding and was reported as showing normal mucous membrane. Over the next few years a chest radiograph showed slight clearing of the lesion in the lower lobe with a progressive shift of the mediastinum to the right. The right pulmonary artery shadow became smaller and was hardly visible in 1963 (Fig. 10). There was also evidence of increased bronchial arterial circulation in the right lung. Clinical examination showed a healthy looking young woman with no clubbing of the fingers and no lymph node enlargement. The pulse was regular and normal in character. The jugular venous pressure was normal. There was a faint pulmonary ejection murmur but the pulmonary component of the second sound was not accentuated and moved normally on respiration. There were signs of fibrosis on the right lung. The haemoglobin was $83 \%$, white cell count $11,400 / \mathrm{mm}^{3}(63 \%$ polymorphs, $4 \%$ eosinophils, $30 \%$ lymphocytes, and 3\% monocytes). The electrocardiogram showed sinus rhythm, a mean frontal QRS vector of $+60^{\circ}$ and no evidence of ventricular hypertrophy. Cardiac catheterization showed a pulmonary artery pressure of $25 / 6 \mathrm{mmHg}$ which rose to $45 / 14 \mathrm{mmHg}$ on exertion. All other pressures were within normal limits. Pulmonary angiograms showed complete obstruction of the right pulmonary artery about $2 \mathrm{~cm}$ from its origin. The left pulmonary artery and veins were normal.

As the haemoptyses persisted and were troublesome, a right thoracotomy was performed by $\mathrm{Mr}$. O. S. Tubbs on 9 August, 1963. The lung was adherent to the parietal pleura by very vascular adhesions. Extrapleural dissection was performed and many vessels were noted to enter the pleura from the chest wall. At the hilum a hard mass was found to be surrounding the right main bronchus and pulmonary artery and was firmly adherent to the back of the superior vena cava. Many of the bronchial arteries entering the lung from the hilum were divided to reduce the risk of haemoptysis, and a biopsy was taken from the mass. This showed dense acellular

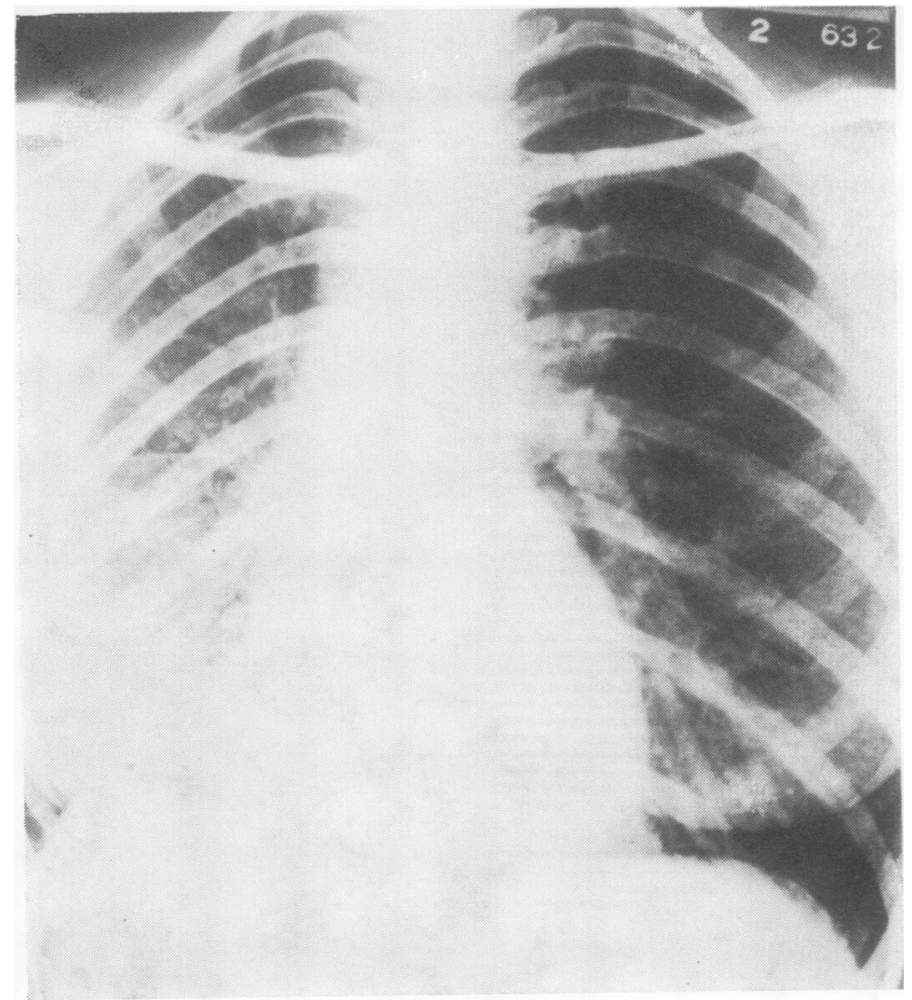

FIG. 10. Case 3. Chest radiograph showing a shift of the mediastinum to the right and diminution in the size of the right pulmonary artery. 
connective tissue with areas of necrosis, calcification, and ossification. There were foci of infiltration by plasma cells and lymphocytes.

The patient had a smooth postoperative course and has had no further severe haemoptysis for the last six years.

\section{DISCUSSION}

Formation of exuberant fibrous tissue in the mediastinum has been recognized since the time of John Hunter (Barrett, 1958). The condition is characterized by the formation of an ill-defined mass which is usually limited to one region of the mediastinum but does not respect any tissue plane and tends to infiltrate and replace the walls of the major vessels and compress adjoining mediastinal structures (McIntire and Sykes, 1949; Salyer, Harrison, Winn, and Taylor, 1959 ; Hache et al., 1962 ; Garamella, Stutzman, Varco, and Jensen, 1955 ; Reed and Stinely, 1959).

Histologically the mass is formed of relatively acellular fibrous tissue made up of intertwining collagen fibres which may be swollen to a degree resembling keloid formation (Fig. 4). The interstices contain few fibroblasts with lymphocytes, many plasma cells, and occasional foci of polymorphonuclear leucocytes. Various degrees of hyalinization, calcification, and ossification may be present.

The clinical presentation depends on the structures invaded and compressed by the fibrous tissue. As the condition tends commonly to affect the superior mediastinum in the region of the superior vena cava and its main tributaries, symptoms and signs of obstruction of that vessel are the commonest presenting features. Mediastinal fibrosis accounts for 10 to $23 \%$ of cases of superior vena cava obstruction as estimated by different authors (McIntire and Sykes, 1949; Failer, 1958). Idiopathic mediastinal fibrosis may be limited to the region of one or both pulmonary hila and produce a typical clinicopathological syndrome for which we suggest the term 'idiopathic pulmonary hilar fibrosis'.

The syndrome consists of: (1) repeated haemoptyses which may be accompanied by shortness of breath; (2) pulmonary hypertension; (3) pleural thickening and diminution in the size of one lung ; (4) segmental narrowing of one or more major bronchi; and (5) unilateral obstruction of the pulmonary artery, pulmonary veins or both.

Hilar fibrosis usually manifests itself at a younger age (15 to 35 years) than the usual type of mediastinal fibrosis, which commonly starts in middle or late life (Barrett, 1958). Both sexes seem to be equally affected.

The syndrome can be classified into two major types, according to whether the obstruction involves mainly the pulmonary artery or veins.

TYPE I This includes patients in whom the pulmonary artery is predominantly affected, as in cases 2 and 3 in this paper and the patients described by Söderberg (1945), Tourniaire et al. (1958), and Nelson, Lundberg, and Dickerson (1965). The haemoptysis is probably related to the development of exuberant bronchopulmonary anastomoses, comparable to those found in Fallot's tetralogy, and congenital absence or hypoplasia of one pulmonary artery (Ambrus, 1936 ; Flynn, Siebens, and Williams, 1954 ; Maier, 1954 ; Elder, Brofman, Kohn, and Charms, 1958 ; Tabakin, Hanson, Adhikari, and Miller, 1960 ; Yacoub, Belcher, and Pattinson, 1965 ; Yacoub, Pattinson, and Ohnsorge, 1965). Chest radiographs show a shift of the mediastinum towards the affected side, diminution in the size of the pulmonary artery shadow, and pleural thickening. A hilar shadow due to the fibrosing mass may be seen. Pulmonary hypertension is present when both the main branches of the pulmonary artery are affected or when the pulmonary veins are involved. Diminution in the size of the lung is possibly related to the narrowing of the pulmonary artery; this has been observed in patients with congenital absence of that vessel (Smart and Pattinson, 1956 ; Sherrick, Kincaid, and DuShane, 1962 ; Oakley, Glick, and McCredie, 1963) or after its experimental ligation (Schlaepfer, 1926).

Pleural thickening is related to repeated chest infections and development of collateral vessels between the lung and the chest wall. Segmental narrowing of one of the main bronchi seems to be a constant feature and serves to differentiate the condition from other causes of compression of the pulmonary artery. Angiograms and differential lung function tests show diminution or complete absence of pulmonary artery flow to the affected lung with low or absent oxygen uptake. It is to be noted that interruption of pulmonary artery flow to one lung does not necessarily mean that this lung has no respiratory function (Landrigan, Purkis, Roy, and Cudkowicz, 1963). This is because the increased collateral bronchial circulation may be useful in eliminating $\mathrm{CO}_{2}$ and so reducing the physiological dead space and the obligatory minute ventilation. In addition, oxygen uptake by the affected lung may occur during periods of hypoxia due to the creation of 
a diffusion gradient between the bronchial blood and alveolar gas.

TYPE II This type includes patients in whom the main pulmonary veins are predominantly affected, as in case 1 and the patients described by Friedberg (1948), Edwards and Burchell (1951), Andrews (1957), Bindelglass and Trubowitz (1958), Botticelli, Schlueter, and Lange (1966), and Cheris and Dadey (1967).

Severe haemoptysis may occur ; this is due to pulmonary capillary hypertension and is comparable to haemoptysis in patients with mitral stenosis or cor triatriatum (Niwayama, 1960 ; McGuire, Nolan, Reeve, and Dammann, 1965). Pulmonary hypertension is a common feature in these patients and may be accompanied by signs of right ventricular failure. The chest radiograph usually shows pulmonary venous congestion localized to one side with thickening of the pleura and diminution in the size of the affected lung. An ill-defined hilar shadow may be present. Segmental narrowing affecting some of the bronchi near the hilum can be demonstrated by bronchoscopy or bronchography. Cardiac catheterization shows elevation of the pulmonary artery pressure which may be equal to systemic arterial level. The right ventricular end-diastolic pressure may also be elevated. One of the characteristic findings is that the wedge pressure in the affected lobe or lung is much higher than the left atrial pressure obtained directly by transeptal or retrograde technique. This is due to postcapillary obstruction and contrasts with the normal wedge pressure obtained in patients with pulmonary hypertension due to pulmonary fibrosis (Hecht, 1956). Differential lung function tests show evidence of obstructive and restrictive disease of the affected lung; in addition, the diffusing capacity of that lung is reduced (Botticelli et al., 1966).

Histologically the affected lung shows striking changes. Apart from the dense fibrosing hilar mass, there are diffuse changes affecting the pulmonary vessels, alveolar walls, and pleura. The walls of the main veins are completely replaced by the surrounding fibrous tissue; the fibrous mass usually extends for a variable distance inside the lung and invades the walls of one or more large bronchi leading to thickening of the wall and concentric narrowing of the affected segment. The fibrous tissue extends through the bronchial cartilage and results in destruction of mucosal glands and other specialized structures producing marked mucosal thickening (Dozois, Bernatz,
Woolner, and Andersen, 1968). The intrapulmonary veins show fibrous thickening of the adventitia and intimal proliferation. The muscular pulmonary arterioles show marked thickening of the wall mainly due to intimal proliferation (Fig. 5). Some of these vessels show complete obliteration of the lumen by organized thrombus with evidence of recanalization (Fig. 6). These changes are most probably secondary to pulmonary venous hypertension and are similar to those described by Heath and Edwards (1959) in patients with pulmonary venous hypertension due to other causes. Pulmonary vascular thrombosis is seen in conditions with impaired pulmonary flow (Harris and Heath, 1962). The alveoli contain 'heart failure' cells and in some areas the interalveolar septa are thickened by fibrous tissue (Fig. 7) resembling interstitial fibrosis (fibrosing alveolitis) (Scadding, 1964). This has led some workers to believe that some cases of interstitial fibrosis are secondary to pulmonary venous obstruction (Andrews, 1957). The visceral pleura is markedly thickened by fibrous tissue and contains a meshwork of moderately large collateral channels. The development of many collateral channels has been demonstrated in animals after ligation of the pulmonary veins (Hurwitz, Calabresi, Cooke, and Liebow, 1954). These collaterals are capable of carrying $20 \%$ of the normal pulmonary flow (Kistner, Mudd, and Hanlon, 1955).

The clinical diagnosis of idiopathic hilar fibrosis is suggested by the presence of evidence of pulmonary vascular obstruction, pleural thickening, and a long, smooth bronchial stricture in a young adult with a history extending over several years. In some cases the presence of a neoplastic process can be difficult to exclude without thoracotomy. The manifestations of type II idiopathic pulmonary hilar fibrosis can be closely simulated by another obscure disease 'primary pulmonary venous sclerosis', which affects the intrapulmonary veins leading to their narrowing (Höra, 1934; Mallory, 1937 ; Könn, 1956; Brewer and Humphreys, 1960 ; Bürki, 1963 ; Stovin and Mitchinson, 1965 ; Brown and Harrison, 1966). The differentiating features are the absence of a hilar mass or bronchial involvement in 'pulmonary venous sclerosis'.

Although the fibrosing process in mediastinal and hilar fibrosis is self-limiting and tends to remain stationary after the first few months in the course of the disease, the damage to the lung is permanent and secondary changes in the pul- 8 monary arterioles may be progressive. This is in 
contrast to patients with superior vena cava obstruction in whom the symptoms remain stationary and are ameliorated by the development of collaterals as time passes (Barrett, 1958). Hilar fibrosis may cause incapacitating symptoms, as in the patients described by Botticelli et al. (1966), or may be directly responsible for death, as in the patients described by Edwards and Burchell (1951), Hegglin and Zollinger (1954), and Bindelglass and Trubowitz (1958). The prognosis depends on the extent of involvement of the main pulmonary vessels and on whether one or both hila are involved. In the three patients described in this paper the condition affected one lung and all three patients seem to have reached the stable stage with only mild disability, except for repeated haemoptyses which were relieved by resection of the affected lung in case 1 , by thoracotomy in case 2 , and by ligation of the bronchial arteries in the hilum in case 3.

At present medical treatment is of no avail at any stage. Surgical correction of the obstruction to the vessels is usually not feasible due to the extent of the fibrosing mass which tends to extend into the substance of the lung; this, however, should be considered in every patient as it offers the only chance of radical cure. Attempts at dilating the bronchial stricture bronchoscopically may lead to excessive bleeding which may be fatal, as in one of the cases reported from the Mayo Clinic (Dozois et al., 1968).

The aetiology of mediastinal and hilar fibrosis remains obscure. The gross and histological similarity of the two conditions to other dense sclerosing conditions affecting other organs and the coincidence of two or more of these rare conditions in one patient suggest a common aetiology (Barrett, 1958). These conditions include mediastinal fibrosis, retroperitoneal fibrosis (Ormond, 1948 ; Bradfield, 1953 ; Raper, 1956), Riedel's struma, sclerosing cholangitis, and ligneous perityphilitis, and were given the name 'multifocal fibrosclerosis' by Comings, Skubi, Van Eyes, and Motulsky (1967). The association of two or more of these conditions was first reported by Tubbs (1946), and later by Inkley and Abbott (1961), Buckberg, Dilley and Longmire Jr. (1966), Morgan, Loughridge, and Calne (1966), Bartholomew et al. (1963), and others. A genetic factor is suggested by the findings of Comings et al. (1967) who reported two brothers, one developing orbital pseudotumour and retroperitoneal fibrosis and the other sclerosing mediastinitis which was followed by the development of orbital pseudotumour and Riedel's thyroditis. The role of infective granulomata, especially histoplasmosis, in producing mediastinal fibrosis has been stressed by many workers (Kunkel et al., 1954 ; Salyer et al., 1959; Marshall, Edmundowicz, and Andrews, 1964 ; Fifer, Woellner, and Gordon, 1955). In one of the patients described in our paper, organisms resembling Histoplasma capsulatum were identified in the biopsy specimen. Methysergide, a drug used for the treatment of migraine, was thought to be responsible for causing retroperitoneal fibrosis in several patients (Graham, 1964 ; Utz, Rooke, Spittel, and Bartholomew, 1965 ; Freestone, 1965). The possible relationship between retroperitoneal fibrosis and malignant tumours has been pointed out by Trever (1958) and Buckberg et al. (1966). No such relationship has been described in patients with mediastinal fibrosis. Auto-immune mechanisms have been incriminated by Que and Mandema (1964) who found persistent hyperglobulinaemia and antinuclear factors in a patient with retroperitoneal fibrosis. Further study of patients with these diseases is needed to elucidate their causes which may be helpful in prevention and treatment.

We should like to thank Mr. O. S. Tubbs and Mr. N. R. Barrett for their kind permission to publish details of cases 1 and 2 .

\section{REFERENCES}

Ambrus, G. (1936). Congenital absence of the right pulmonary artery with bleeding into the right lung. $J$. techn. Meth., 15, 103.

Andrews, E. C., Jr. (1957). Five cases of an undescribed form of pulmonary interstitial fibrosis caused by obstruction of the pulmonary veins. Bull. Johns Hopk. Hosp., 100, 28.

Barrett, N. R. (1958). Idiopathic mediastinal fibrosis. Brit. J. Surg., 46, 207.

Bartholomew, L. G., Cain, J. C., Woolner, L. B., Utz, D. C., and Ferris, D. O. (1963). Sclerosing cholangitis: Its possible association with Riedel's struma and fibrous retroperitonitis-report of two cases. New Engl. J. Med., 269, 8.

Bindelglass, I. L., and Trubowitz, S. (1958). Pulmonary vein obstruction: an uncommon sequel to chronic fibrous mediastinitis. Ann. intern. Med., 48, 876.

Botticelli, J. T., Schlueter, D. P., and Lange, R. L. (1966). Pulmonary venous and arterial hypertension due to chronic fibrous mediastinitis: Hemodynamics and pulmonary function. Circulation, 33, 862.

Bradfield, E. O. (1953). Bilateral ureteral obstruction due to envelopment and compression by an inflammatory retroperitoneal process. J. Urol. (Baltimore), 69, 769.

Brewer, D. B., and Humphreys, D. R. (1960). Primary pulmonary hypertension with obstructive venous lesions. Brit. Heart J., 22, 445. 
Brown, C. H., and Harrison, C. V. (1966). Pulmonary veno-occlusive disease. Lancet, 2, 61.

Buckberg, G. D., Dilley, R. B., and Longmire, W. P., Jr. (1966). The protean manifestations of sclerosing fibrosis. Surg. Gynec. Obstet., 123, 729.

Bürki, K. (1963). Eine primäre isolierte obliterierende Pulmonalvenenveränderung als Ursache eines chronischen Cor pulmonale. Arch. Kreisl.-Forsch., 40, 35.

Cameron, D. G., Ing, S. T., Boyle, M., and Mathews, W. H. (1961). Idiopathic mediastinal and retroperitoneal fibrosis. Canad. med. Ass. J., 85, 227.

Cheris, D. N., and Dadey, J. L. (1967). Fibrosing mediastinitis: an unusual cause for cor pulmonale. Amer. $J$. Roentgenol., 100, 328.

Comings, D. E., Skubi, K. B., Van Eyes, J., and Motulsky, A. G. (1967). Familial multifocal fibrosclerosis: findings suggesting that retroperitoneal fibrosis, mediastinal fibrosis, sclerosing cholangitis, Riedel's thyroiditis, and pseudotumor of the orbit may be different manifestations of a single disease. Ann. intern. Med., 66, 884 .

Dozois, R. R., Bernatz, P. E., Woolner, L. B., and Andersen, H. A. (1968). Sclerosing mediastinitis involving major bronchi. Mayo Clin. Proc., 43, 557.

Edwards, J. E., and Burchell, H. B. (1951). Multilobar pulmonary venous obstruction with pulmonary hypertension: "Protective" arterial lesions in the involved lobes. Arch. intern. Med., 87, 372.

Elder, J. C., Brofman, B. L., Kohn, P. M., and Charms, B. L. (1958). Unilateral pulmonary artery absence or hypoplasia. Circulation, 17, 557.

Erganian, J., and Wade, L. J. (1943). Chronic fibrous mediastinitis with obstruction of the superior vena cava. J. thorac. Surg., 12, 275.

Failer, H. J. (1958). Superior vena caval obstruction. Thesis, Graduate School, University of Minnesota.

Fifer, W. R., Woellner, R. C., and Gordon, S. S. (1955). Mediastinal histoplasmosis: report of three cases with dysphagia as the presenting complaint. Dis. Chest, 47, 518 .

Flynn, J. E., Siebens, A. A., and Williams, S. F. (1954). Congenital absence of a main branch of the pulmonary artery. Amer. J. med. Sci., 228, 673.

Freestone, D. S. (1965). Possible retroperitoneal fibrosis and methysergide. Lancet, 1, 1168.

Friedberg, S. A. (1948). Hemoptysis secondary to chronic mediastinal venous obstruction. Ann. Otol. (St. Louis), $57,897$.

Garamella, J. J., Stutzman, F. L., Varco, R. L., and Jensen, N. K. (1955). Subcarinal mediastinal granulomas causing esophageal obstruction. J. thorac. Surg., 30, 187.

Graham, J. R. (1964). Methysergide for prevention of headache: experience in 500 patients over three years. New Engl. J. Med., 270, 67.

Hache, L., Woolner, L. B., and Bernatz, P. E. (1962). Idiopathic fibrous mediastinitis. Dis. Chest., 41, 9.

Harris, P., and Heath, D. (1962). The Human Pulmonary Circulation, p. 242, chap. 21. Livingstone, Edinburgh and London.

Heath, D., and Edwards, J. E. (1959). Histological changes in the lung in diseases associated with pulmonary venous hypertension. Brit. J. Dis. Chest, 53, 8.

Hecht, H. H. (1956). Heart failure and lung disease. Circulation, 14, 265 .

Hegglin, R., and Zollinger, H. (1954). Über einen Fall von Pulmonalsklerose besonderer Ätiologie (Narbengewebe im Mediastinum). Cardiologia (Basel), 24, 92.
Höra, J. (1934). Zur Histologie der klinischen "Primären Pulmonalsklerose". Frankfurt Z. Path., 47, 100.

Hurwitz, A., Calabresi, M., Cooke, R. W., and Liebow, A. A. (1954). An experimental study of the venous collateral circulation of the lung. I. Anatomical observations. Amer. J. Path., 30, 1085.

Inkley, S. R., and Abbott, G. R. (1961). Unilateral pulmonary arteriosclerosis: unusual fibrous connective tissue growth associated. Review of literature and discussion of possible physiological mechanisms involved in these changes. Arch. intern. Med., 108, 903.

Kistner, W. F., Mudd, J. G., and Hanlon, C. R. (1955) Bronchospirometric determinations of pulmonary function in dogs after unilateral ligation of the pulmonary vein and artery. (Abstract.) Circulation, 12, 733.

Knox, L. C. (1925). Chronic mediastinitis. Amer. J. Med. Sci., 169, 807.

Könn, G. (1956). Die pathologische Morphologie der Lungengefässe bei chronischem Cor pulmonale. Beitr. path. Anat., 116, 273.

Kunkel, W. M., Jr., Clagett, O. T., and McDonald, J. R. (1954). Mediastinal granulomas. J. thorac. Surg., 27,565 .

Landrigan, P. L., Purkis, I. E., Roy, D. E., and Cudkowicz, L. (1963). Cardio-respiratory studies in a patient with an absent left pulmonary artery. Thorax, 18, 77.

Maier, H. C. (1954). Absence or hypoplasia of a pulmonary artery with anomalous systemic arteries to the lung. J. thorac. Surg., 28, 145.

Mallory, T. B. (1937). Case records of the Massachusetts General Hospital, Case 23511. New Engl. J. Med., 217, 1045 .

Marshall, R. J., Edmundowicz, A. C., and Andrews, C. E. (1964). Chronic obstruction of the superior vena cava due to histoplasmosis. Circulation, 29, 604.

McGuire, L. B., Nolan, T. B., Reeve, R., and Dammann, J. F. (1965). Cor triatriatum as a problem of adult heart disease. Circulation, 31, 263.

McIntire, F. T., and Sykes, E. M. Jr. (1949). Obstruction of the superior vena cava: a review of the literature and report of two personal cases. Ann. intern. Med., 30, 925.

Morgan, A. D., Loughridge, L. W., and Calne, R. Y. (1966). Combined mediastinal and retroperitoneal fibrosis Lancet, 1, 67.

Nelson, W. P., Lundberg, G. D., and Dickerson, R. B. (1965). Pulmonary artery obstruction and cor pulmonale due to chronic fibrous mediastinitis. Amer. J. Med., 38, 279.

Niwayama, G. (1960). Review: Cor triatriatum. Amer. Heart J., 59, 291.

Oakley, C., Glick, G., and McCredie, R. M. (1963). Congenital absence of a pulmonary artery. Amer. J. Med. 34, 264.

Ormond, J. K. (1948). Bilateral ureteral obstruction due to envelopment and compression by an inflammatory $\mathbb{D}$ retroperitoneal process. J. Urol. (Baltimore), 59, 1072.

Que, G. S., and Mandema, E. (1964). A case of idiopathic $\square$ retroperitoneal fibrosis presenting as a systemic collagen $O$ disease. Amer. J. Med., 36, 320.

Raper, F. P. (1956). Idiopathic retroperitoneal fibrosis $\frac{\Omega}{\mathbb{D}}$ involving the ureters. Brit. J. Urol., 28, 436.

Reed, W. G., and Stinely, R. W. (1959). Massive periaortic and periarterial fibrosis. Report of a case. New Engl. J. Med., 261, 320. 
Salyer, J. M., Harrison, H. N., Winn, D. F., Jr., and Taylor, R. R. (1959). Chronic fibrous mediastinitis and superior vena caval obstruction due to histoplasmosis. Dis. Chest, 35, 364.

Scadding, J. G. (1964). Fibrosing alveolitis. Brit. med. J., 2, 686 and 941 .

Schlaepfer, K. (1926). The effect of the ligation of the pulmonary artery of one lung without and with resection of the phrenic nerve. Arch. Surg., 13, 623.

Sherrick, D. W., Kincaid, O. W., and DuShane, J. W. (1962). Agenesis of a main branch of the pulmonary artery. Amer. J. Roentgenol., 87, 917.

Smart, J., and Pattinson, J. N. (1956). Congenital absence of left pulmonary artery. Brit. med. J., 1, 491.

Söderberg, G. (1945). Om striktur av arteria pulmonalis genom skrumpnande mediastinit. Nord. Med., 28, 2051.

Stovin, P. G. I., and Mitchinson, M. J. (1965). Pulmonary hypertension due to obstruction of the intrapulmonary veins. Thorax, 20, 106.

Tabakin, B. S., Hanson, J. S., Adhikari, P. K., and Miller, D. B. (1960). Physiologic studies in congenital absence of the left main pulmonary artery. Circulation, 22, 1107.
Tourniaire, A., Treppoz, M., Tartulier, M., Deyrieux, F., and Van Straaten, G. (1958). Coeur pulmonaire chronique par compression artérielle pulmonaire dans la maladie du hile d'origine ganglionnaire. Arch. Mal. coeur., 51, 960.

Tubbs, O. S. (1946). Superior vena caval obstruction due to chronic mediastinitis. Thorax, 1, 247.

Trever, R. W. (1958). Reticulum-cell sarcoma producing retroperitoneal and periureteric fibrosis. Report of a case. New Engl. J. Med., 258, 268.

Utz, D. C., Rooke, E. D., Spittell, J. A., Jr., and Bartholomew, L. G. (1965). Retroperitoneal fibrosis in patients taking methysergide. J. Amer. med. Ass., 191, 983.

Yacoub, M. H., Belcher, J. R., and Pattinson, J. N. (1965). Unilateral pulmonary artery hypoplasia associated with congenital cardiac anomalies. Brit. J. Dis. Chest, 59, 102.

Pattinson, J. N., and Ohnsorge, J. (1965). Angeborene Hypoplasie einer Lungenarterie. Thoraxchirurgie und vaskuläre Chirurgie, 13, 346. 